\title{
HLA-DRB1 alleles associated with polymyalgia rheumatica in northern Italy: correlation with disease severity
}

\author{
Carlo Salvarani, Luigi Boiardi, Vilma Mantovani, Andrea Ranzi, Fabrizio Cantini, \\ Ignazio Olivieri, Michela Bragliani, Elisa Collina, PierLuigi Macchioni
}

Servizio di

Reumatologia,

Arcispedale S Maria

Nuova, Reggio Emilia,

Italy

C Salvarani

L Boiardi

P L Macchioni

\section{Laboratorio}

Centralizzato, Settore

Tipizzazione Tissutale,

Ospedale S

Orsola-Malpighi,

Bologna, Italy

V Mantovani

M Bragliani

E Collina

Cattedra di Biometria e Statistica Medica,

Istituto di Igiene,

Università di Modena,

Italy

A Ranzi

Unità Reumatologica, Ospedale di Prato,

Prato, Italy

F Cantini

Unità di

Reumatologia,

Ospedale S Carlo,

Potenza, Italy

I Olivieri

Correspondence to:

Dr C Salvarani, Servizio di

Reumatologia, Azienda

Ospedaliera Arcispedale S

Maria Nuova, $\mathrm{V}$ le Umberto

1 N50, 42100 Reggio Emilia,

Italy.

Accepted for publication

15 February 1999

\begin{abstract}
Objective-To examine the association of HLA-DRB1 alleles with polymyalgia rheumatica (PMR) in a Mediterranean country and to explore the role of HLADRB1 genes in determining disease sever-
\end{abstract} ity.

Methods-A five year prospective follow up study of 92 consecutive PMR patients diagnosed by the secondary referral centre of rheumatology of Reggio Emilia, Italy was conducted. HLA-DRB1 alleles were determined in the 92 patients, in 29 DR4 positive rheumatoid arthritis (RA) patients, and in 148 controls from the same geographical area by polymerase chain reaction amplification and oligonucleotide hybridisation.

Results-No significant differences were observed in the frequencies of HLA-DRB1 types and in the expression of HLA-DRB 70-74 shared motif between PMR and controls. The frequency of the patients with double dose of epitope was low and not significantly different in PMR and in controls. No significant differences in the distribution of HLA-DR4 subtypes were observed between DR4+ PMR, DR+ RA, and DR4+ controls. Results of the univariate analysis indicated that an erythrocyte sedimentation rate (ESR) at diagnosis > $72 \mathrm{~mm} \mathrm{1st} \mathrm{h}$, the presence of HLA-DR1, DR10, rheumatoid epitope, and the type of rheumatoid epitope were significant risk factors associated with relapse/ recurrence. Cox proportional hazards modelling identified two variables that independently increased the risk of relapse/recurrence: $\mathrm{ESR}$ at diagnosis $>72$ $\mathrm{mm} 1 \mathrm{st} h(\mathrm{RR}=1.5)$ and type 2 (encoded by a non-DR4 allele) rheumatoid epitope ( $\mathbf{R R}=2.7)$.

Conclusion-These data from a Mediterranean country showed no association of rheumatoid epitope with PMR in northern Italian patients. A high ESR at diagnosis and the presence of rheumatoid epitope encoded by a non-DR4 allele are independent valuable markers of disease severity.

(Ann Rheum Dis 1999;58:303-308)

An association between DR4 and polymyalgia rheumatica (PMR), particularly in patients with giant cell arteritis (GCA), has been observed. ${ }^{12}$ Recently, some studies have evalu- ated the HLA-DRB1 alleles associated with PMR. Studies done on white PMR patients originating from the United Kingdom (Manchester area) and from Minnesota (Mayo Clinic) have found an association with HLA$\mathrm{DRB} 1{ }^{\star} 04$ alleles, ${ }^{34}$ similar to that seen in rheumatoid arthritis (RA). A key role of HLADRB $1{ }^{\star} 04$ subtypes (DRB1*0401, ${ }^{\star} 0404$ / $\left.0408,{ }^{\star} 0405\right)$ in RA severity has been clearly demonstrated by Weyand et $a l,{ }^{5}$ while few studies have analysed the relation between HLADR4 and PMR severity. ${ }^{267}$ In Italy, as in other Mediterranean countries, DR4 is weakly associated to RA. ${ }^{8}$ However, this association becomes stronger in seropositive patients with more severe disease (presence of erosions, or extra-articular manifestations, or both).

A subset of PMR patients present with a persistent active disease (around 30\% in Reggio Emilia experience) that requires long term corticosteroid treatment for the occurrence of relapse/recurrence when corticosteroid treatment is reduced or stopped. ${ }^{9}{ }^{10}$

In this study we have evaluated the association between PMR and HLA-DRB1 alleles in a consecutive series of PMR patients diagnosed in a Mediterranean country (Reggio Emilia, Italy) over a five year period. These patients were prospectively followed up, permitting the evaluation of the influence of HLA-DRB1 genes and other clinical and laboratory parameters on the occurrence of relapse/recurrence.

\section{Methods}

PMR PATIENTS

Ninety two consecutive new PMR patients were identified in the Reggio Emilia metropolitan area over a five year period (1992-96). Table 1 shows the clinical and demographic characteristics of the patients. PMR was diagnosed when all the following were present $^{11}$ : (1) persistent pain (for at least one month) involving two of the following areas: neck, shoulders, and/or pelvic girdle; (2) morning stiffness lasting more than one hour; (3) rapid response to prednisone $(\leqslant 20 \mathrm{mg} /$ day), and (4) absence of other diseases capable of causing the musculoskeletal symptoms. Only patients over the age of 50 were included. All PMR patients were rheumatoid factor negative. Eighty two patients had an erythrocyte sedimentation rate (ESR) greater than $40 \mathrm{~mm}$ $1 \mathrm{st} h$ at diagnosis. Ten patients with typical clinical symptoms, ESR $<40 \mathrm{~mm} 1 \mathrm{st} h$ (median $28 \mathrm{~mm} \mathrm{1st} \mathrm{h}$; range: $14-38 \mathrm{~mm} 1 \mathrm{st} \mathrm{h}$ ) and rapid and complete response to cortico- 
Table 1 Demographic and clinical characteristics at diagnosis of the 92 PMR patients studied

Female/male (\%)

Age at onset of disease (y)

Duration of disease before diagnosis (months)

Duration of treatment (months)

Duration of follow up (months)

Systemic symptoms and signs (fever, anorexia, weight loss)

Morning stiffness ( $\mathrm{min}$ )

Peripheral synovitis

Distal swelling with pitting oedema

Biopsy confirmed GCA

Initial prednisone dose ( $\mathrm{mg} /$ day)

Cumulative prednisone dose (g)

Cumulative prednisone dose before the first relapse/recurrence $(\mathrm{g})^{\star}$

ESR at diagnosis $(\mathrm{mm} / 1 \mathrm{st} \mathrm{h})$

$\mathrm{CRP}$ at diagnosis $(\mathrm{mg} / \mathrm{dl})$

ESR $<30 \mathrm{~mm} / 1$ st $\mathrm{h}$ at diagnosis (\%)

Relapse/recurrence (\%)

$75 / 25$
$72(7)$
$2.9(1.5)$
$31(23)$
$44(27)$
$49 \%(45)$
$160(60)$
$23.9 \%(22)$
$8.7 \%(8)$
$6.5 \%(6)$
$19.5(11.0)$
$6.5(4.8)$
$3.6(3.1)$
$77(29)$
$6.1(4.1)$
$7.6 \%(7)$
$44 \%(40)$

Data are expressed as percentage or mean (SD). ${ }^{\star}$ The dose was computed only for the 40 patients with at least one relapse/recurrence.

steroids were also included. All these 10 patients had increased $C$ reactive protein (CRP) values at diagnosis (median: $2.1 \mathrm{mg} / \mathrm{dl}$; range: $1.2-5.0 \mathrm{mg} / \mathrm{dl}$ ).

Temporal artery biopsy specimens were obtained only in patients with cranial signs or symptoms and the diagnosis of GCA was based on a positive temporal artery biopsy. No patient satisfied, at diagnosis, the American Rheumatism Association (ARA) 1987 revised criteria for RA. ${ }^{12}$

RA PATIENTS

Twenty nine HLA-DR4 positive RA patients fulfilling the ARA 1987 revised criteria for RA were investigated. These patients represented all the DR4 positive patients resident in Reggio Emilia seen as out patients during a one year period (1992) in the Reggio Emilia Rheumatology Unit (all of these patients were also included in a immunogenetic study on RA). ${ }^{13}$ Seventy six per cent of the patients were seropositive and $72 \%$ had erosive disease.

CONTROL GROUP

The healthy control group consisted of a pool of 148 unrelated blood donor volunteers from the same geographical area. HLA-DRB1 alleles were also determined in 41 DR4 positive healthy controls belonging to a larger control group constituted by 351 blood donors from the same geographical area.

FOLLOW UP STUDY

All the 92 patients with PMR were clinically assessed by the same physician at presentation, monthly for the first six months, then every three months during the follow up period. A standardised data collection form was used at every visit to record medical informations. Age, sex, location of aching and morning stiffness, the presence of systemic manifestations and biopsy confirmed GCA, the dose and duration of corticosteroids, and the occurrence of relapses and recurrences were registered. The cumulative prednisone dose was computed. The presence of swelling and tenderness of the joints and periarticular structures with and without pitting oedema, tenosynovitis (defined by the presence of swelling and tenderness along a well defined tenosynovial structure) and the clinical symptoms and the physical findings specific for carpal tunnel syndrome were carefully assessed at each visit. Electromyography (EMG) was performed when considered diagnostically useful. Joint radiography was performed in all patients with joint swelling at some time point during the course of the illness.

At diagnosis and during the follow up ESR was determined by Westergren method and CRP was measured by nephelometry (NA latex CRP kit, Behringwerke, Marburg, Germany) (upper limit of the normal reference range 0.5 $\mathrm{mg} / \mathrm{dl}$ ) in all patients.

Relapse and/or recurrence were considered present if articular symptoms or signs occurred (usually with an ESR greater than $30 \mathrm{~mm} \mathrm{1st}$ h) in a patient receiving corticosteroids or after withdrawal of treatment, respectively. The symptoms were suppressed by resumption of, or increase in corticosteroid dose.

The end of the disease was the date of permanent discontinuation of treatment without relapse or recurrence. The end point of patient follow up was the date of the last clinic visit or the date of death.

Only one patient died during the follow up. The cause of death was stroke and at the time of death the disease was in remission and the patient receiving treatment with prednisone $2.5 \mathrm{mg} /$ day.

At the end point of follow up 39 patients $(42.4 \%)$ were still being treated with corticosteroids, while 53 patients $(57.6 \%)$ had suspended treatment. Twenty patients had taken corticosteroids for less than two years and at least one year of follow up without treatment after the suspension of corticosteroids. The mean (SD) duration of corticosteroid treatment was 15.9 (5.0) months in these 20 patients. Twenty three patients were receiving corticosteroid treatment for more than four years. The mean (SD) duration of corticosteroid treatment was 67.2 (18.7) months. The cumulative prednisone dose was significantly higher in the patients with more than four years of corticosteroid treatment than in those with less than two years (12.5 g versus $3.8 \mathrm{~g}, \mathrm{p}=$ $0.0001)$.

Throughout the follow up period, no PMR patients fulfilled the 1987 ARA revised criteria for $R^{12}$ and no clinical evidence of joint deformity or radiological evidence of erosions were observed.

\section{HLA-DNA TYPING}

Genomic DNA was extracted from whole blood of patients and controls by using a rapid salting out method. ${ }^{14}$ A low resolution HLADRB1 molecular typing was performed by polymerase chain reaction amplification with sequence specific primers (PCR-SSP), as previously described. ${ }^{15}$ This method allowed us to type 18 DRB1 alleles, including DRB $1{ }^{\star} 0101 / 2$ and ${ }^{\star} 0103$. HLA-DRB $1{ }^{\star} 04$ subtypes were distinguished by PCR amplification of DRB1 genes and sequence specific oligotyping using $32 \mathrm{P}$-end labelled probes, according to the 11th Histocompatibility Workshop protocol. ${ }^{16}$ 
Table 2 HLA-DR frequencies in total PMR, PMR with and without distal manifestations, and healthy controls

\begin{tabular}{|c|c|c|c|c|c|c|c|}
\hline & $\begin{array}{l}\text { Controls } \\
(n=148)\end{array}$ & $\begin{array}{l}P M R \text { total } \\
(n=92)\end{array}$ & $\begin{array}{l}p \text { versus } \\
\text { controls }\end{array}$ & $\begin{array}{l}\text { PMR without distal } \\
\text { manifestations* } \\
(n=62)\end{array}$ & $\begin{array}{l}p \text { versus } \\
\text { controls }\end{array}$ & $\begin{array}{l}\text { PMR with distal } \\
\text { manifestations* } \\
(n=30)\end{array}$ & $\begin{array}{l}p \text { versus } \\
\text { controls }\end{array}$ \\
\hline DR1 & 17.6 & 19.6 & NS & 19.4 & NS & 20 & NS \\
\hline DR15 & 12.2 & 12.0 & NS & 16.1 & NS & 3.3 & NS \\
\hline DR16 & 13.0 & 11.5 & NS & 12.9 & NS & 13.3 & NS \\
\hline DR3 & 12.8 & 22.8 & 0.05 & 19.4 & NS & 30.0 & 0.03 \\
\hline DR4 & 16.2 & 20.7 & NS & 19.4 & NS & 23.3 & NS \\
\hline DR11 & 33.8 & 45.7 & NS & 46.8 & NS & 43.3 & NS \\
\hline DR12 & 2.7 & 3.3 & NS & 1.6 & NS & 6.7 & NS \\
\hline DR13 & 27.7 & 17.4 & NS & 19.4 & NS & 13.3 & NS \\
\hline DR14 & 9.5 & 10.9 & NS & 11.3 & NS & 10 & NS \\
\hline DR7 & 26.4 & 18.5 & NS & 16.1 & NS & 23.3 & NS \\
\hline DR8 & 10.8 & 2.2 & 0.05 & 1.6 & 0.05 & 3.3 & NS \\
\hline DR9 & 2.0 & 0.0 & NS & 0.0 & NS & 0.0 & NS \\
\hline DR10 & 1.4 & 3.3 & NS & 3.2 & NS & 3.3 & NS \\
\hline Epitope $70-74$ & 24.3 & 30.4 & NS & 29.9 & NS & 32.3 & NS \\
\hline
\end{tabular}

^Distal manifestations included the presence of peripheral synovitis and/or distal pitting oedema. Data shown as percentages.

\section{STATISTICAL ANALYSIS}

Statistical analysis was done using SPSS statistical package (SPSS Inc, Chicago, Illinois). The $\chi^{2}$ test with Yates's correction and Fisher's exact test were used to compare the frequencies of HLA antigens. The $t$ test for independent values was used when necessary. Relative risks (RR) were calculated using the Woolf method.

The end point in the survival analysis was the occurrence of at least one relapse/recurrence (the first in the case of more than one) during the follow up. Univariate analysis (KaplanMeier method) was used to estimate the cumulative probability of not having relapse/ recurrence in relation to the following variables: age (five year interval periods), sex, presence or absence of GCA, systemic signs/ symptoms, peripheral synovitis, distal extremity swelling with pitting oedema. ESR at diagnosis (> $72 \mathrm{~mm} \mathrm{1st} \mathrm{h,} \leqslant 72 \mathrm{~mm} 1 \mathrm{st} \mathrm{h}$ ), CRP at diagnosis $(>5.8 \mathrm{mg} / \mathrm{dl}, \leqslant 5.8 \mathrm{mg} / \mathrm{dl})$, the presence or absence of HLA-DRB1 alleles, rheumatoid epitope and the type of rheumatoid epitope ( $1=$ epitope encoded by an HLA-DR4

Table 3 Frequency of associated DRB1 alleles in polymyalgia rheumatica and controls

\begin{tabular}{|c|c|c|c|c|}
\hline$H L A-D R B 1$ alleles & $\begin{array}{l}P M R \\
(n=92)\end{array}$ & $\begin{array}{l}\text { Controls } \\
(n=148)\end{array}$ & $p$ & $R R(C I)$ \\
\hline $\mathrm{DRB} 1^{\star} 0101,02$ & 19.6 & 16.2 & NS & $1.3(0.6,2.5)$ \\
\hline $\mathrm{DRB} 1^{\star} 0103$ & 0.0 & 1.4 & NS & - \\
\hline $\mathrm{DRB} 1^{\star} 0401$ & 7.6 & 4.7 & NS & $1.7(0.6,4.9)$ \\
\hline $\mathrm{DRB} 1{ }^{\star} 0402$ & 1.1 & 3.4 & NS & $0.3(0.04,2.7)$ \\
\hline $\mathrm{DRB} 1{ }^{\star} 0403$ & 4.3 & 3.4 & NS & $1.3(0.3,5.0)$ \\
\hline DRB $1^{\star} 0404$ & 3.3 & 1.4 & NS & $2.5(0.4,15.0)$ \\
\hline $\mathrm{DRB} 1^{\star} 0405$ & 0.0 & 2.0 & NS & - \\
\hline $\mathrm{DRB} 1^{\star} 0406$ & 1.1 & 0.7 & NS & $1.6(0.1,26.1)$ \\
\hline DRB $1^{\star} 0407$ & 3.3 & 0.7 & NS & $5.0(0.5,48.4)$ \\
\hline $\mathrm{DRB} 1{ }^{\star} 0408$ & 0.0 & 0.7 & NS & - \\
\hline DRB1*1001 & 3.3 & 1.4 & NS & $2.5(0.4,15)$ \\
\hline Epitope $70-74$ & 30.4 & 24.3 & NS & $1.4(0.8,2.4)$ \\
\hline $\mathrm{DRB} 1^{\star} 04, \mathrm{X} \dagger$ & 9.9 & 6.7 & NS & $1.5(0.5,4.4)$ \\
\hline $\mathrm{DRB} 1^{\star} 01, \mathrm{Y} \ddagger$ & 20.0 & 17.6 & NS & $1.2(0.6,2.3)$ \\
\hline
\end{tabular}

$\nmid \mathrm{X}$ denotes any DRB1 allele other than ${ }^{\star} 01 . \neq \mathrm{Y}$ denotes any DRB1 allele other than ${ }^{\star} 04$.

Table 4 Frequency of DRB1 04 subtypes in DR4+ PMR patients compared with DR4+ $R A$ patients and with DR4+ healthy controls

\begin{tabular}{|c|c|c|c|c|c|c|c|}
\hline DR4 subtypes & $\begin{array}{l}\text { Controls } \\
(n=41)\end{array}$ & $\begin{array}{l}P M R \\
(n=19)\end{array}$ & $p$ & $R R(C I)$ & $\begin{array}{l}R A \\
(n=29)\end{array}$ & $p$ & $R R(C I)$ \\
\hline $\mathrm{DRB} 1{ }^{\star} 0401$ & 22 & 37 & NS & $2.1(0.7,7.0)$ & 34 & NS & $2.0(0.7,5.5)$ \\
\hline DRB $1{ }^{\star} 0402$ & 15 & 5 & NS & $0.3(0.04,3.0)$ & 7 & NS & $0.5(0.1,2.7)$ \\
\hline $\mathrm{DRB} 1{ }^{\star} 0403$ & 10 & 21 & NS & $2.5(0.6,11.5)$ & 10 & NS & $1.1(0.2,5.5)$ \\
\hline $\mathrm{DRB} 1{ }^{\star} 0404$ & 24 & 16 & NS & $0.6(0.2,2.5)$ & 21 & NS & $0.9(0.3,3.0)$ \\
\hline DRB $1{ }^{\star} 0405$ & 20 & 0 & 0.05 & - & 21 & NS & $1.2(0.4,4.1)$ \\
\hline $\mathrm{DRB} 1{ }^{\star} 0406$ & 2 & 5 & NS & $2.3(0.1,38.5)$ & 0 & NS & - \\
\hline $\mathrm{DRB} 1{ }^{\star} 0407$ & 10 & 16 & NS & $1.8(0.4,8.9)$ & 7 & NS & $0.7(0.1,4.1)$ \\
\hline $\mathrm{DRB} 1^{\star} 0408$ & 5 & 0 & NS & - & 0 & NS & - \\
\hline
\end{tabular}

Data shown as percentages. allele, $2=$ epitope encoded by a non-DR4 allele and $3=$ no dose of epitope) were also considered. Youden's index was used to calculate the pre-assigned cut off value for ESR and CRP (this index identifies the value that best maximises both sensitivity and specificity using ROC curve).

The difference between curves was assessed using the log rank test. Cox propotional hazards models were used to evaluate the relation between the occurrence of at least one relapse/recurrence and the previously defined variables. Only the variables significant at the 0.05 level were chosen for the multivariate analysis.

\section{Results}

Analysis of HLA-DR frequencies in PMR showed a significant increase of DR3 in PMR patients compared with controls (table 2). DR4 was only slightly more frequent in PMR patients, while no differences were observed for DR1 antigen. The frequency of DR8 was significantly lower in PMR patients. However, the significance of DR3 positive and DR8 negative associations was lost when the $p$ value was corrected for the number of antigens tested.

Table 3 shows the frequencies of HLADRB1 types in PMR and controls. No significant differences were observed between PMR and controls. We did not observe any significant association of PMR with the HLA-DRB 70-74 shared motif. The frequency of double dose of epitope was very low both in PMR patients ( 3 of $92,3.3 \%$ ) and in controls ( 3 of $148,2.0 \%$ ), and the difference was not significant. No significant associations were observed comparing the frequencies of the epitope encoded by an HLA-DR4 allele and a non-DR4 allele in PMR and controls.

Table 4 represents the distribution of HLADR4 subtypes between DR4+ PMR, DR4+ RA, and DR4+ controls. DRB $1{ }^{\star} 0405$ was significantly less frequent in PMR compared with controls. However, the significance was lost when the $\mathrm{p}$ value was corrected for the number of antigens tested.

Thirty of $92(32.6 \%)$ patients presented at diagnosis peripheral synovitis (22 patients) and distal extremity swelling with pitting oedema (eight patients). No statistically significant 
Table 5 Univariate analysis of seven factors significantly related to the risk of relapse/recurrence of polymyalgia rheumatica based on the Kaplan-Meier method

\begin{tabular}{|c|c|c|c|c|}
\hline Variables & Number & $\begin{array}{l}\text { Relapse } \\
\text { /recurrence }\end{array}$ & $p$ & $\begin{array}{l}\text { Estimated relative hazard } \\
\text { ( } 95 \% \text { confidence intervals) }\end{array}$ \\
\hline \multicolumn{5}{|c|}{ Peripheral arthritis } \\
\hline Presence & 50 & 24 & \multirow[t]{2}{*}{0.04} & $1.44(0.62,3.33)$ \\
\hline Absence & 41 & 16 & & 1.0 (reference) \\
\hline \multicolumn{5}{|c|}{ Distal extremity swelling with pitting oedema } \\
\hline Presence & 12 & 4 & \multirow[t]{2}{*}{0.02} & 1.0 (reference) \\
\hline Absence & 79 & 36 & & $1.67(0.47,6.02)$ \\
\hline \multicolumn{5}{|c|}{$\operatorname{ESR}(\mathrm{mm} \mathrm{1st} \mathrm{h)}$} \\
\hline$\leqslant 72$ & 41 & 14 & \multirow[t]{2}{*}{0.02} & 1.0 (reference) \\
\hline$>72$ & 50 & 26 & & $2.09(0.89,4.89)$ \\
\hline \multicolumn{5}{|l|}{ HLA-DR1 } \\
\hline Presence & 17 & 9 & \multirow[t]{2}{*}{0.01} & $1.56(0.54,4.50)$ \\
\hline Absence & 74 & 31 & & 1.0 (reference) \\
\hline \multicolumn{5}{|l|}{ HLA-DR10 } \\
\hline Presence & 3 & 2 & \multirow[t]{2}{*}{0.005} & $2.63(0.23,30.11)$ \\
\hline Absence & 88 & 38 & & 1.0 (reference) \\
\hline \multicolumn{5}{|c|}{ Rheumatoid epitope } \\
\hline Presence & 27 & 15 & \multirow[t]{2}{*}{0.02} & $1.95(0.79,4.85)$ \\
\hline Absence & 64 & 25 & & 1.0 (reference) \\
\hline \multicolumn{5}{|c|}{ Type of rheumatoid epitope } \\
\hline 1 & 7 & 4 & \multirow[t]{3}{*}{0.001} & $2.07(0.43,10)$ \\
\hline 2 & 15 & 9 & & $2.33(0.75,7.30)$ \\
\hline 3 & 69 & 27 & & 1.0 (reference) \\
\hline
\end{tabular}

Table 6 Significant variables (at 0.05 level) identified by Cox proportional hazards model

\begin{tabular}{llll}
\hline Variables & $\begin{array}{l}\text { Regression } \\
\text { coefficient }\end{array}$ & $p$ value & $\begin{array}{l}\text { Relative risk (95\% confidence } \\
\text { intervals) }\end{array}$ \\
\hline Type of rheumatoid epitope & -0.60 & 0.11 & $0.55(0.26,1.14)$ \\
1 & 0.99 & 0.002 & $2.68(1.45,4.94)$ \\
2 & - & - & 1.0 (reference) \\
3 & - & - & 1.0 (reference) \\
ESR (mm 1st h) & 0.42 & 0.02 & $1.52(1.06,2.19)$ \\
$\quad \leqslant 72$ & & &
\end{tabular}

associations with DR4, DR1, and rheumatoid epitope were observed when comparing patients with distal manifestations at diagnosis with controls (table 2). During the follow up period 14 other patients developed at least one episode of peripheral arthritis and/or distal extremity swelling with pitting oedema. Globally, 44 patients $(47.8 \%)$ developed peripheral arthritis and/or distal swelling with pitting oedema. No significant associations with DR4, DR1, and rheumatoid epitope were observed in these 44 patients (data not shown).

The frequencies of HLA-DR4 and HLADR10 were not significantly different between the 20 patients with a corticosteroid treatment duration of less than two years and at least one year of follow up without treatment after corticosteroid suspension and the 23 patients with a treatment duration of more than four years (30.0\% versus $21.7 \%$ and $0 \%$ versus $4.3 \%$, respectively), while the frequency of HLADR1 was significantly higher in the latter group $(21.7 \%$ versus $0 \%, \mathrm{p}=0.03, \mathrm{RR}=2.1,95 \% \mathrm{CI}$ : $1.5,2.9)$. The frequency of rheumatoid epitope was higher in the patients with more than four years of corticosteroid treatment $(34.8 \%$ versus $25.0 \%$ ), however the difference was not significant.

Results of the univariate analysis indicated that a ESR at diagnosis $>72 \mathrm{~mm} 1 \mathrm{st} \mathrm{h}$, the presence of HLA-DR1, DR10, rheumatoid epitope, and the type of rheumatoid epitope were significant risk factors associated with relapse/recurrence (table 5).

Cox proportional hazards modelling identified two variables that independently increased the risk of relapse/recurrence: ESR at diagnosis $>72 \mathrm{~mm} 1 \mathrm{st} \mathrm{h}$ and type 2 (encoded by a nonDR4 allele) rheumatoid epitope (table 6).

\section{Discussion}

We did not observe any significant association between HLA-DRB ${ }^{\star} 04$ and 01 alleles and $P M R$ in our Italian population. The frequency of HLA-DRB 70-74 shared epitope was similar in PMR patients and in healthy controls. At double dose, the frequency of this epitope was very low in PMR patients, as it was in controls. The distribution of HLA-DR4 subtypes was similar in PMR, RA and normal controls.

Studies on British or American white PMR patients attending respectively Manchester and Mayo Clinic rheumatology centres observed a significant association with HLA-DRB $1^{\star} 04$ allele. ${ }^{34}$ In the British study HLA-DRB ${ }^{\star} 04$ subtyping showed an increase in the frequencies of both $\mathrm{DRB} 1{ }^{\star} 0401$ and $\mathrm{DRB} 1{ }^{\star} 0404$ antigens, similar to RA immunogenetic profile. ${ }^{4}$ In the Mayo study the PMR patients were associated to all HLA-DRB ${ }^{\star}{ }^{*} 04$ alleles, unlike RA, where the expression of allelic variants of the HLA-DR4 family was restricted to HLA-DRB $1{ }^{\star} 0401$ and ${ }^{\star} 0404 / 8 .^{3}$ Furthermore, Weyand et al showed, in HLA-DRB $1^{\star} 04$ negative PMR patients, an underrepresentation of HLA-DRB $1{ }^{\star} 01$ alleles; this haplotype was, instead, frequently seen in DRB $1^{\star} 04$ negative $\mathrm{RA}$ patients. Unlike the results of the Mayo study, Haworth et al showed a significantly higher frequency of DRB $1{ }^{\star} 0101$ in PMR patients compared with controls. $^{4}$

Furthermore, successive European studies have reported conflicting results on the association of PMR with HLA-DRB1 ${ }^{\star} 04$ or 01 alleles. The first French study from Lille showed in PMR patients a higher frequency of DRB $1^{\star} 0101$, but no association with DR4. ${ }^{17}$ However, a study from Mediterranean France (Montpellier) showed that phenotype DRB $1^{\star} 04$ was significantly increased in PMR patients compared with normal controls, but the frequency of HLA-DRB $1^{\star} 01$ was not significantly different from that of controls. ${ }^{7}$ In a recent study from Switzerland no significant association of DR4 and DR1 with PMR was observed. ${ }^{18}$ Only a significant weak association with the HLA-DRB1 70-74 shared motif $(\mathrm{OR}=1.8)$ was demonstrated, and this association was lost when the $\mathrm{p}$ value was corrected. Three studies considered, among others, a group of patients with RA. ${ }^{3718}$ The association of DR4 with RA was much stronger than that observed in PMR. Similarly, we observed in Italian RA patients an association, even if weak, with DR4 $(\mathrm{RR}=2.4),{ }^{8}$ but no association with PMR. No association with HLA-DR4 and DR1 was also observed in the subgroup of PMR patients with distal musculoskeletal manifestations, who had a disease presentation closer to RA.

HLA-DR4 association in Italian RA patients was stronger in seropositive disease $(R R=3.8)$ and in patients with extra-articular features $(\mathrm{RR}=4.0)$ and erosions $(\mathrm{RR}=3.0) .{ }^{8}$ Seronegative RA, like PMR, showed a frequency of DR4 
allele identical to that observed in Italian controls. Elderly Italian seronegative patients presented, in many cases, a benign disease more related to PMR than to seropositive RA. ${ }^{19}$

The discrepancies in the association of PMR with HLA-DRB $1^{\star} 04$ or 01 , or both, observed in the previously mentioned studies may be explained by the different ethnic background of the population studied. The frequency of DR4 is higher in northern European white populations compared with those observed in southern European countries. ${ }^{2468}$ In the Reggio Emilia and Lille areas, where the frequency of DR4 in general population was the lowest observed (16\%), no association of this allele with PMR was observed. ${ }^{17}$

Differences in the referral pattern of the patients enrolled in these studies could also explain some different results. As evidenced for RA, ${ }^{5820}$ DR 4 or DR1, or both, could be a less important marker for susceptibility to PMR than they are for disease severity.

There seem to be two subsets of PMR patients. One subset presents with mild, limited disease, the other has persistent disease needing long term treatment ( $>2$ years).$^{21}$ The patients with more severe disease experience, during the follow up, one or more episodes of relapse/recurrence and they constituted about $30 \%$ of the patients in the Reggio Emilia series. ${ }^{9}$ The long term use of corticosteroids in PMR causes important morbidity. ${ }^{22}$ Few studies have tried to identify risk factors associated with PMR severity. No reliable predictors of duration of corticosteroid treatment have been found. The longer duration of corticosteroid treatment observed in women by Chuang et $a l^{23}$ has not been confirmed by other studies. ${ }^{9}{ }^{10} \mathrm{~A}$ reduced percentage of CD8 cells after six months of treatment has also been proposed as a useful outcome parameter. ${ }^{24}$ However, Corrigall et al found that the \%CD8 T cell was not a good indicator of disease activity. ${ }^{25}$

Few PMR studies have examined the association between rheumatoid epitope and disease severity. DR4 was found to be increased in patients with GCA and disabling PMR at diagnosis. ${ }^{2}$ Other studies have not found any association between peripheral synovitis and rheumatoid epitope. ${ }^{61826}$ Uddhammar et al followed up 47 patients for three years. ${ }^{6}$ No difference in the percentages of DR4 positive and DR4 negative PMR patients still receiving corticosteroid treatment at the end of follow up was observed.

Recently, Combe et al did not observe in PMR and GCA any association between HLA$\mathrm{DRB} 1^{\star}$ genes and markers of disease activity including number of relapses and disease duration. ${ }^{7}$ However, the follow up design of this study and definition of relapses were not clearly defined. Furthermore, the authors mixed together patients with PMR alone, GCA alone and patients with both the conditions.

We observed a significantly higher frequency of HLA-DR1 in the patients with more than four years of corticosteroid treatment than in those with a corticosteroid treament duration of less than two years and one year follow up period without treatment. No significant differ- ences in DR4 frequencies were observed between these two groups.

To include all the patients we evaluate in a multivariate analysis the risk factors associated with relapse/recurrence, considering clinical and laboratory parameters and HLA-DRB1* antigens. This study provides evidence that high ESR at diagnosis ( $>72 \mathrm{~mm} 1 \mathrm{st} \mathrm{h}$ ) and the presence of rheumatoid epitope encoded by a non HLA-DR4 allele are independent risk factors of relapse/recurrence. These data confirm that DR1 may have a prognostic value in identifying the patients with more severe disease. A high ESR at diagnosis ( $>72 \mathrm{~mm} \mathrm{1st} \mathrm{h}$ ) is an independent risk factor of relapse/recurrence.

In conclusion, our data from a Mediterranean country show no association between HLA-DRB ${ }^{\star}{ }^{\star}$ alleles and rheumatoid epitope and PMR. No differences in the distribution of HLA-DR4 subtypes were observed between PMR, RA, and normal controls.

However, the presence of rheumatoid epitope encoded by a non-DR4 allele (particularly DR1) and a high ESR at diagnosis are independent valuable markers of disease severity.

1 Richardson JE, Gladman DD, Fam A, Keystone EC. HLADR4 in giant cell arteritis: association with polymyalgia heumatica syndrome. Arthritis Rheum 1987;30:1293-7.

2 Cid M-C, Ercilla G, Vilaseca J, Sanmarti R, Villalta J, Ingelmo $\mathrm{M}$, et al. Polymyalgia rheumatica: a syndrome associated with HLA-DR4 antigen. Arthritis Rheum 1988, 31:678-82

3 Weyand CM, Hunder NNH, Hicok KC, Hunder GG Goronzy JJ. HLA-DRB1 alleles in polymyalgia rheumatica, giant cell arteritis, and rheumatoid arthritis. Arthritis Rheum 1994;37:514-20.

4 Haworth S, Ridgeway J, Stewart I, Dyer PA, Pepper L, Ollier W. Polymyalgia rheumatica is associated with both HLA-DRB $1^{\star} 0401$ and DRB $1^{\star} 0404 . \mathrm{Br} \mathrm{J}$ Rheumatol 1996;35:632-5.

5 Weyand CM, McCarthy TG, Goronzy JJ. Correlation between disease phenotype and genetic heterogeneity in between disease phenotype and genetic heterogen
rheumatoid arthritis. J Clin Invest 1995;95:2120-6.

6 Uddhammar A, Nilsson Sojka BN, Rantapää-Dahlqvist S: HLA antigens in polymyalgia rheumatica in Northern Sweden. Clin Rheumatol 1996;15:486-90.

7 Combe B, Sany J, Le Quellec A, Clot J, Eliaou J-F. Distribution of HLA-DRB1 alleles of patients with polymyalgia rheumatica and giant cell arteritis in a Mediterranean population. J Rheumatol 1998;25:94-8.

8 Salvarani C, Macchioni PL, Mantovani W, Rossi F, Veneziani M, Boiardi L, et al. Extraarticular manifestations of rheumatoid arthritis and HLA antigens in Northern Italy. J Rheumatol 1992;19:242-6.

9 Salvarani C, Macchioni PL, Tartoni PL, Rossi F, Baricchi R, Castri C, Chiaravallot F, et al. Polymyalgia rheumatica and giant cell arteritis: a 5- year epidemiologic and clinical giant cell arteritis: a 5- year epidemiologic and clinical
study in Reggio Emilia, Italy. Clin Exp Rheumatol 1987;5: study in

10 Ayoub WT, Franklin CM, Torretti D. Polymyalgia rheumatica. Duration of therapy and long-term outcome. Am J Med 1985;79:309-15.

11 Healey LA. Long-term follow-up of polymyalgia rheumatica: evidence for synovitis. Semin Arthritis Rheum 1984;13:322-8.

12 Arnett FC, Edworthy SM, Bloch DA, McShane DJ, Fries JF,Cooper NS, et al. The American Rheumatism Association 1987 revised criteria for the classification of rheumatoid arthritis. Arthritis Rheum 1988;31:315-24.

13 Salvarani C, Macchioni P, Mantovani W, Bragliani M, Collina E, Cremonesi T, et al. HLA-DRB1alleles associated with rheumatoid arthritis in Northern Italy: correlation with disease severity. Br J Rheumatol 1998;37:165-9.

14 Miller SA, Dykess DD, Polesky HF. A simple salting ou procedure for extracting DNA from human nucleated cell Nucleic Acids Res 1988;16:1215.

15 Mantovani V, Martinelli G, Bragliani M, Buzzi M, Selva P, Collina E, et al. Molecular analysis of HLA genes for the selection of unrelated bone marrow donor. Bone Marrow Transplant 1995;16:329-35.

16 Kimura A, Sasazuki T. Eleventh International Histocompatibility Workshop reference protocol for the HLA DNAtyping technique. In: Tsuji K, Aizawa M, Sasazuki T, eds. typing technique. In: T suji K, Aizawa M, Sasazuki T, eds. patibility Workshop and Conference. Oxford: Oxford Science, patibility Works

17 Labbe P, Flipo RM, Fajardy I, Hachulla E, Houvenagel E, Hatron PY, et al. Etude du polymorphisme HLA-DRB1 au 
cours de la pseudopolyarthrite rhizomélique et de la maladie de Horton. Rev Med Interne 1995;16:778-81.

18 Guerne P-A, Salvi M, Seitz M, Bruhlmann P, Rivier G, Frey $\mathrm{D}$, et al. Molecular analysis of HLA-DR polymorphism in polymyalgia rheumatica. J Rheumatol 1997;24:671-6.

19 Salvarani C, Zizzi F, Macchioni PL, Rossi F, Georgountzos A, Valentini M, et al. Uno studio clinico dell'artrite reumatoide dell'anziano. Confronto con un gruppo di pazient con malattia insorta prima dei 60 anni. Il Reumatologo 1990;3:107-12.

20 Thomson W, Pepper L, Payton A, Carthy D, Scott D, Ollier W, et al. Absence of an association between HLA$\mathrm{DRB} 1^{\star} 04$ and rheumatoid arthritis in newly diagnosed cases from the community. Ann Rheum Dis 1993;52:539cases

21 Salvarani C, Macchioni PL, Boiardi L. Polymyalgia rheumatica. Lancet 1997;350:43-7.

22 Gabriel SE, Sunku J, Salvarani C, O'Fallon M, Hunder GG: Adverse outcomes of antiinflammatory therapy among patients with polymyalgia rheumatica. Arthritis Rheum 1997;40:1873-8

23 Chuang T-Y, Hunder GG, Ilstrup DM, Kurland LT Polymyalgia rheumatica: a 10-year epidemiologic and cllnical study. Ann Intern Med 1982;97:672-80

24 Salvarani C, Boiardi L, Macchioni PL, Rossi F, Tartoni P, Casadei Maldini M, et al. The role of peripheral CD8 lymphocytes and soluble IL-2 receptor in predicting the duration of corticosteroid treatment in polymyalgia rheumatica and giant cell arteritis. Ann Rheum Dis 1995;54:640-4.

25 Corrigall VM, Dolan AL, Dasgupta B, Panayi GS. The sequential analysis of $\mathrm{T}$ lymphocyte subsets and interleukin- 6 in polymyalgia rheumatica patients as predictors of disease remission and steroid withdrawal. Br J tors of disease remission and

26 Salvarani C, Rossi F, Macchioni PL, Mantovani W, Veneziani M, Boiardi L, et al. Synovitis in polymyalgia rheumatica: an immunogenetic study. [Letter]. Br J Rheumatol 1992;31:720 